\title{
Natural Gas Compressibility Factor Correlation Evaluation for Niger Delta Gas Fields
}

\author{
Obuba, J*. ${ }^{1}$, Ikiesnkimama, S.S. ${ }^{2}$, Ubani, C. E. ${ }^{3}$, Ekeke, I. C. ${ }^{4}$ \\ ${ }^{12}$ Petroleum/Gas, Engineering/University of Port Harcourt, Nigeria \\ ${ }^{3}$ Department of Petroleum and Gas Engineering University of Port Harcourt Port Harcourt, Rivers State. \\ ${ }^{4}$ Department of Chemical Engineering Federal University of Technology Oweri, Imo State Nigeria.
}

\begin{abstract}
Natural gas compressibility factor (Z) is key factor in gas industry for natural gas production and transportation. This research presents a new natural gas compressibility factor correlation for Niger Delta gas fields. First, gas properties databank was developed from twenty-two (22) laboratory Gas PVT Reports from Niger Delta gas fields. Secondly, the existing natural gas compressibility factor correlations were evaluated against the developed database (comprising 22 gas reservoirs and 223 data sets). The developed new correlation was used to compute the z-factors for the four natural gas reservoir system of dry gas, solution gas, rich $\mathrm{CO}_{2}$ gas and rich condensate gas reservoirs, and the results were compared with some exiting correlations. The performances of the developed correction indicated better statistical ranking, good graph trends and best crossplots parity line when compared with correlations evaluated. From the results the new developed correlation has the least standard error and absolute error of (stdEr) of $1.461 \%$ and $1.669 \%$ for dry gas; $6.661 \%$ and $1.674 \%$ for solution; $7.758 \%$ and $6.660 \%$ for rich $\mathrm{CO}_{2}$ and $7.668 \%$ and $6.661 \%$ for rich condensate gas reservoirs. The new correlation also show high correlation coefficient of: $93.39 \%$, for dry gas; $89.24 \%$ for solution gas; $83.56 \%$ for rich $\mathrm{CO}_{2}$ and $83.34 \%$ for rich Condensate gas reservoirs. Also the proposed new model maintained good graphical trends for four z-factors matched it: experimental, estimated (Standing - Katz) and the best evaluated correlation when matched. Very good crossplots parity line performance when compared with the evaluated correlations. It could then be concluded that the new developed correlation and that of Papay correlation are most appropriate correlations for calculating natural compressibility for Niger Delta gas fields. Carr, Kobayashi, and Burrows (1954) and Wichert-Aziz (1972), correction factor methods; were applied to correct the presence of non-hydrocarbons. But the major setbacks on laboratory analyses for PVT behavior are sometimes expensive and time consuming. Correlations, which are used to predict gas compressibility factor, are much easier and faster than equations of state, invariably save cost.
\end{abstract}

Key words: Niger Delta Gas, developing Compressibility factor, Evaluation, Correlations.

\section{Introduction}

The world now is shifting its energy demand to natural gas. This could be as result of the environmental friendly of natural gas, rapid depletion of world's crude oil reserves and higher degree of calories of natural gas when compared with that of crude oil. Nigeria is counted as one of the world's largest gas nation. As stated by Oil and Gas Overview MBendi, ${ }^{[1]}$ ' informed that Nigeria's Natural gas proved reserves is 5.29 trillion cubic meters, ranking $8^{\text {th }}$ positions of the world's natural gas proved reserves, as reported in BP Statistics Energy Survey ${ }^{[2]}$.

Recent studies show that, if Nigeria could rigorously pursue the production of natural gas as that of crude oil in next couple of years will boost the country's income to 15 billion US dollars. Although, Nigeria is now turning to its vast gas reserves as the money spinner of the future to the country. With exports from the LNG plant on Bonny Island rising, Nigeria said it expects to see gas bringing in as much income in 10 years as oil does, World Energy ${ }^{[3]}$. For these reasons this study was orchestrated to proffers natural gas compressibility factor correlations that will be suitable for Niger delta gas fields. The natural gas compressibility factor is a measure of the amount of the gas deviate from perfect gas behavior. In gas industry, it is an important tool for computing reservoir fluid properties either directly or indirectly. The application of this important factor ranges: evaluation of gas, gas flow in pipes, material balance calculations, well analysis, numerical reservoir simulations, etc.

The industry standard is to measure gas properties: Pressure - Volume - Temperature (PVT) of reservoir in laboratory using reservoir sample. The compressibility factor $(\mathrm{Z})$ was introduced into gas industry to correct the deviation of ideal gas behaviour. The deviation of gases from the ideal gas behaviour at high 
temperature and pressure depends on the composition of the gas. Many equation of state have been developed by many authors in the attempt to correct the pressure-volume-temperature variables for real gas with experimental data. To correct some assumptions so far made in relationship to ideal gas deviation, a correction factor known as gas compressibility factor was introduced.

Many correlation methods for compressibility factor have been developed by many authors. Generally, computation of compressibility factor can be done by empirical method, correlation method, corresponding state method and as well as use of equation of state. The position of gas deviation factor in today's gas industry is still a prominent one. It is one of the factors oil and gas industries cannot do without. In today standard treatment of phase behavior requires the use of gas compressibility factor to operate. To this end Nigerian natural gas industries need to relied on as more and more natural gas reservoirs are been discovered in onshore and offshore of Nigeria. Therefore, it becomes a necessity to have a simple and robust correlation(s) to be able to determine z-factor values accurately. This project presents methods that allow accurate determination of $\mathrm{z}$ factor values both for pure components and gas mixtures including significant amounts of non-hydrocarbon components.

Accurate estimation of compressibility factor $(Z)$ is very essential, most especially when it comes to quick estimation of initial gas in place. It is also an important factor to rely on when dealing on gas metering, where the volume flow of gas obtained from the orifice meter depends on the accuracy of the Z-factor. Moreover, now that clean energy is in demand, it therefore stands that accurate estimate of existing gas reserves and developing methods for the recovery of gas from reservoir as well as the capacity to design surface facilities to handle this gas. For instance, percent error $(21 \%)$ in the value of compressibility factor cause about $9 \%$ error in the volume of metering gas which many eventually lead to loss of dollar by the supplier or the buyer of gas.

Standing and Katz Z-factor correlation is very reliable and has been used with confidence by industry for more than 35 years for estimation of mixtures composed of pure hydrocarbon gases. Ikoku, ${ }^{[11]}$; Ahmed ${ }^{[5]}$. The main issue for this study is that Nigeria has been rated $7^{\text {th }}$ world largest gas nation with estimated reserve about 184 trillion cubic feet of natural gas reserves found mainly in Niger Delta region Kupolokun, ${ }^{[14]}$. The exploitation of the Niger Delta enrich gas reservoir for commercial purpose is new and therefore, there is the need to evaluate exist correlations to determine the most suitable Z-factor for proper estimate and exploration of the natural gas reserves in this region. This is the main aim of this study. Moreover, some of the correlations perform better depending on geographical and geological of particular area they were developed for.

The knowledge of the pressure, volume, and temperature relationship plays a significant role in studying ideal gas behaviour. According to Ahmed, ${ }^{[5]}$, use of equations of state high at pressure could leads to errors of $500 \%$, which is so high when compared with atmospheric pressure of 2-3\%. Ideally, as pointed by Savidge $2000^{[12]}$, gas compressibility factor was conceived as the means to account for the deviation of real gas behavior from the behaviour of an ideal gas. The value of natural gas deviation factor Z, can be obtained in two major different ways: laboratory experimental and equations of states.

The industry standard is to measure gas properties, Pressure-Volume- Temperature (PVT), in laboratory using reservoir samples Standing, ${ }^{[9]}$. But the major setbacks on laboratory analyses for PVT behavior are sometimes expensive and time consuming. Correlations, which are used to predict gas compressibility factor, are much easier and faster than equations of state. Therefore, the objective of this work is to develop a robust $\mathrm{z}$ factor correlation which can use to predict Niger Delta natural gas easily. As defined by Perrot, Pierre ${ }^{[16]}$, an equation of state is a thermodynamics equation describing the state of matter under a given set of physical conditions. Mathematically, equation of state is defined ideally, as;

$$
p V=n R T
$$

While $\mathrm{n}$ is defined as the weight of the gas $\mathrm{m}$ divided by the molecular weight $\mathrm{M}$. Terak ${ }^{[5]}$, , by definition

$$
n=\frac{m}{M}
$$

Combining Eqns 2.1 with 2.2 gives;

$$
P v=\left(\frac{m}{M}\right) R T
$$

Where $\mathrm{m}=$ molecular of gas, $\mathrm{lb}$

$$
\mathrm{M}=\text { molecular weight, } \mathrm{lb} / \mathrm{ft}^{3}
$$

but $\mathrm{m}=\mathrm{m} / \mathrm{v}=$ density $\rho$

and

Where:

$$
\rho_{g}=\frac{m}{v}=\frac{p M}{R T}
$$


$\mathrm{P}=$ pressure, psia

$\mathrm{V}=$ volume of gas, $\mathrm{ft}^{3}$

$\mathrm{n}=$ number of pound moles of gas

$\mathrm{R}=$ universal gas constant $=10.732 \mathrm{psiaft}^{3} /{ }^{\circ} \mathrm{R}-\mathrm{lbm}-\mathrm{mol}$;

$\mathrm{T}=$ temperature, ${ }^{\circ} \mathrm{R}$.

$\mathrm{Z}=$ dimensionless gas deviation factor or compressibility factor

and thus:

$$
Z=\frac{P V_{\mathrm{m}}}{R T}
$$

\section{Principle of Corresponding State}

The unique relationship between the compressibility factor and the reduced temperature, $T_{r}$, and the reduced pressure, $P_{r}$, was first recognized by van der Waals in 1873 and is known as the two-parameter principle of corresponding states. The principle of corresponding states expresses the generalization that the properties of a gas which are dependent on molecular forces are related to the critical properties of the gas in a universal way. That provides a most important basis for developing correlations of molecular properties. Hong Wei Xiang ${ }^{[10]}$.

As for the compressibility of gases, the principle of corresponding states indicates that any pure gas at the same reduced temperature, $T_{r}$, and reduced pressure, $P_{r}$, should have the same compressibility factor.. The reduced temperature and pressure are defined as:

$$
T_{r}=\frac{T}{T_{c}}
$$

and

$$
P_{r}=\frac{P}{P_{c}}
$$

$\mathrm{T}_{\mathrm{c}}$ and $\mathrm{P}_{\mathrm{c}}$ are known as the critical temperature and critical pressure of a gas. They are characteristics of each specific gas with $T_{c}$ being the temperature above which it is not possible to liquefy a given gas and

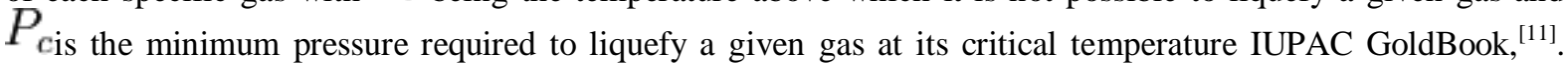
Together they define the critical point of a fluid above which distinct liquid and gas phases of a given fluid do not exist. In natural gas calculation pseudocritical pressure and temperature help to correlate the physical properties of mixtures with the principle of corresponding states. This explained that similar gases have the same gas deviation of Z-factor. (Lee, et al, ${ }^{[15]}$

\section{Empirical Correlations Method (Standing-Katz Compressibility Factor Chart)}

Standing and Kat ${ }^{[13]}$ presented a generalized $\mathrm{z}$-factor chart, which has become an industry standard for predicting the volumetric behavior of natural gases. To be able to use this chart, knowledge of reduced temperature and reduced pressure are required, which further needs determination of critical properties (namely, critical pressure and critical temperature of the system). Numerous methods have been suggested to predict pseudocritical properties of the gases as a function of their specific gravity. The point to be noted here is that these methods predict pseudo critical values which are evidently not accurate values of the gas mixtures. The existing methods fail to predict accurate values of pseudocritical values when non-hydrocarbon components are present in significant amounts.

\section{Natural Gas Compressibility Factor Correlations (Direct Calculation)}

After the Standing and Katz ${ }^{[7]}$ compressibility Z-factor chart breakthrough, although it was industrially accepted as standard, but direct methods for computing natural gas Z-factor was obviously necessary due to the tedious and high expensive of Stand-Katz laboratory method. As result, numerous equations state have been developed in the attempt to correlate the pressure-volume-temperature variables for real gases outside experimental data, Ahmed ${ }^{[5]}$. Several empirical calculations for computing Z-factor have been introduced by many authors over the years. Most of these equations of state will be used to test the possibility for developing the needed Z-factor for the Niger Delta gas fields. 
Data Acquisition:

\section{Methodology}

A standard pressure-volume-temperature (PVT) natural gas data reports from renowned laboratories of exploration and producing Petroleum Company operating in Niger Delta Gas fields in Nigeria were used to prepare a database used for the study. Twenty -three (22) natural gas reservoirs were separated into four categories according to natural gas compositions: two (2) dry gas reservoirs, with 24 data sets, twelve (12) solution gas reservoirs consisting 144 data sets, two (2) carbon dioxide rich gas composition 24 data sets and six (6) rich condensate gas reservoirs comprising 45 data sets respectively totaling 237 data sets. These different gas well composition were then computed into different natural properties using Microsoft excel environment. The computed gas properties are; $\mathrm{T}_{\mathrm{c}}, \mathrm{Pc}, \mathrm{Ppr}, \mathrm{Tpr}$, apparent molecular weight, gas density etc, which were used for the development of new Z-factor correlation for Niger Delta gas fields. But before then, the properties were used to evaluate eight different equations of state (EOS): Yarborough and Hall (1973), Burnett (1979), Papp (1979), Dranchuk; Purvis and Robison ${ }^{[8]}$, Dranchuk and Abou Kaseem[7], Briggs and Brill ${ }^{[17]}$, Papay (1968) and Shell Oil Company. The EOS was used as a guide for the development of the new correlation for determining the best correlation(s) for Niger Delta gas fields. Pseudo-reduced pressure (Pr) and temperature (Tr) range were; $0.2 \leq \operatorname{Pr} \leq 8$ and $1.26 \leq \operatorname{Tr} \leq 1.7805$ respectively. Tables 1 show sample of the different PVT reports from different gas fields in Niger Delta used for the correlations.

\subsection{Correlation Developmeent And Comparison}

One of the technical objectives of this study is to develop a new correlation for natural gas compressibility factor for Niger Delta gas fields. This has been achieved by using the developed data bank for Niger Delta gas fields.

$$
Z=6.41824-0.013363 P p r-3.3512937 p r
$$

The steps followed for the development of the new $\mathrm{z}$-factor were the normal application of all the roles used for the computation of natural gas critical pressures and temperatures. We started by separating the gas PVT report into its components, then applying Kay's mixing rule and Carr, Kohayashi-Burrows (1954) correlation to account for the natural gas impurities for accurate $\mathrm{z}$-factor values. Since Nigerian gas is sweet type, i.e. no surphur, as result the Wichert-Aziz correlation were not considered.

Then, in order to know the integrity of the newly developed model the experimental Z- factor and Standing and Katz chart was used to match the new developed correlation. Figures 1 to 4 show the graphical trends of the combined Z-factors: experimental, Standing and Katz, EOS as well as the new correlation.

Also, the new z-facto correlation of natural gas compressibility factor presented in the study show great accuracy statistically. The new compressibility factor $\mathrm{Z}$, has the smallest errors. Among the compressibility factor correlations considered in this study (the equations of state) the new correlation shows the smallest standard error $(\mathrm{Er} \%)$, absolute standard $(\mathrm{Ea} \%)$, least skewness, better centralized kurtosis and highest coefficient of correlation.

\section{Results}

The accuracy of eight (8) different equations of state most often used in natural gas industry for the calculation of gas compressibility factor for natural gases are discussed in this section while the new developed z-factor for Nigerian gas and steps taking for the development are explained (for new developed z-factor correlation for Niger Delta gas fields) the results of eight equations of state used for the computation of the various $z$-factors and that of Standing and Katz estimated chart are shown on Tables 1 to 4 . Prior to the calculations, the concept of Kay's (1936) mixing rule and Stewart-Burkhardt- Voo (1959); were applied to determine the accuracy of the Niger Delta gas mixture compositions (since it is a sweet gas) and low molecular weight, while Wincher-Aziz (1972), correction factor for the presence of non-hydrocarbons, was applied to take care of the presence of Carbon dioxide. Then, a database was established, first of its kindly in Nigerian gas industry for a standard correlation of these different equations of state. Four different reservoir systems: dry gas system, solution gas system, rich carbon dioxide system and condensate rich gas system were computed using the eight different correlation models. At the end, a new correlation model was developed for Niger Delta gas fields, which shows a good fitting when matched with Standing Katz chart. See SK chart. 
Table1: Very Dry Gas Reservoir (PVT Report) Reservoir Temperature: $168{ }^{0} \mathrm{~F}\left(628{ }^{0} \mathrm{R}\right.$

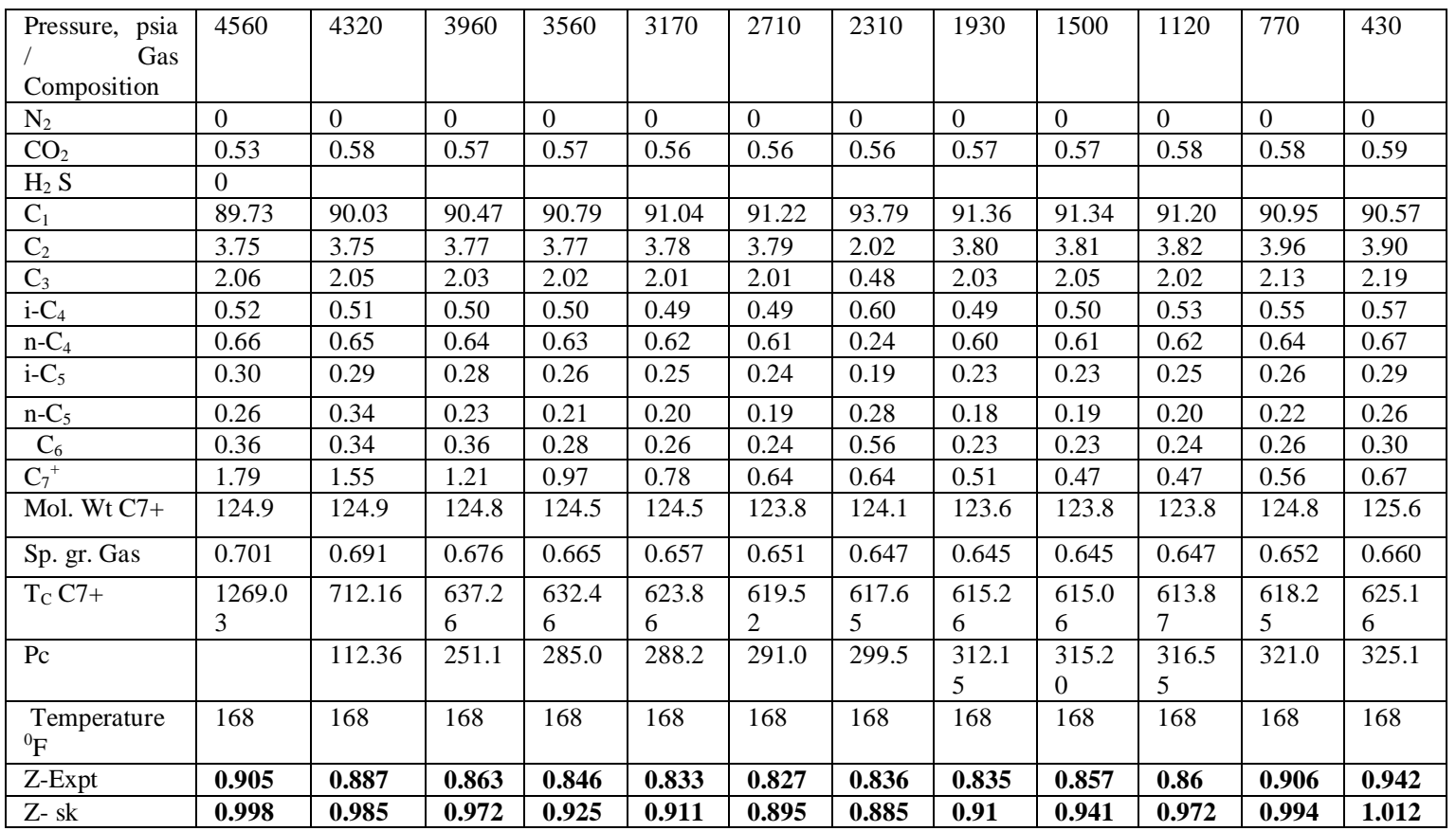

Table 2: Equation of State Z-Factor Computation for Solution Gas Field (Temp. $163{ }^{0} \mathrm{~F}$ )

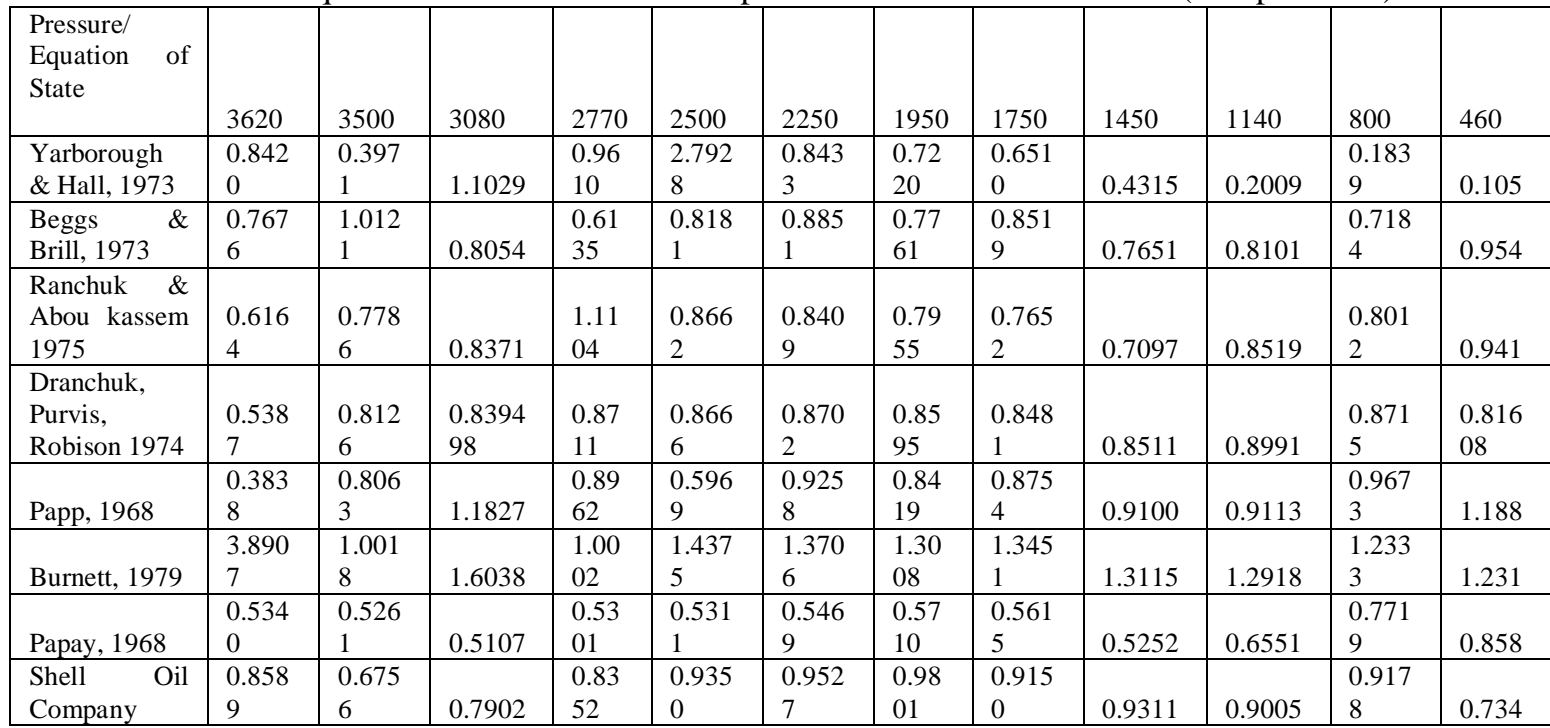

Table 3: Z-Factor Evaluation for New Correlation, Standing - Katz chart and Experiment for solution Gas Reservoirs.

\begin{tabular}{|c|c|c|c|c|c|c|c|c|c|c|c|c|}
\hline & & & Pressu & e, psia & & & & & & & & \\
\hline & 4560 & 4320 & 3960 & 3560 & 3170 & 2710 & 2310 & 1930 & 1520 & 1120 & 770 & 430 \\
\hline Experimental & 0.905 & 0.887 & 0.863 & 0.846 & 0.833 & 0.827 & 0.836 & 0.835 & 0.857 & 0.86 & 0.906 & 0.942 \\
\hline $\begin{array}{l}\text { Standing and } \\
\text { Kartz, } 1942\end{array}$ & 0.998 & 0.985 & 0.972 & 0.925 & 0.911 & 0.895 & 0.885 & 0.91 & 0.941 & 0.972 & 0.994 & 1.012 \\
\hline This Study & 0.785 & 0.775 & 0.740 & 0.712 & 0.697 & 0.689 & 0.694 & 0.690 & 0.698 & 0.715 & 0.747 & 0.774 \\
\hline Papay 1968 & $\begin{array}{l}0.864 \\
4 \\
\end{array}$ & 0.6980 & $\begin{array}{l}0.698 \\
0\end{array}$ & $\begin{array}{l}0.556 \\
4 \\
\end{array}$ & 0.5397 & 0.5388 & 0.5566 & 0.5854 & 0.6500 & 0.7045 & $\begin{array}{l}0.786 \\
5 \\
\end{array}$ & $\begin{array}{l}0.873 \\
1 \\
\end{array}$ \\
\hline
\end{tabular}


Table 4: Rich Carbon Dioxide Z-Factor Evaluation for New Correlation, Standing - Katz chart and Experiment for Gas Reservoirs

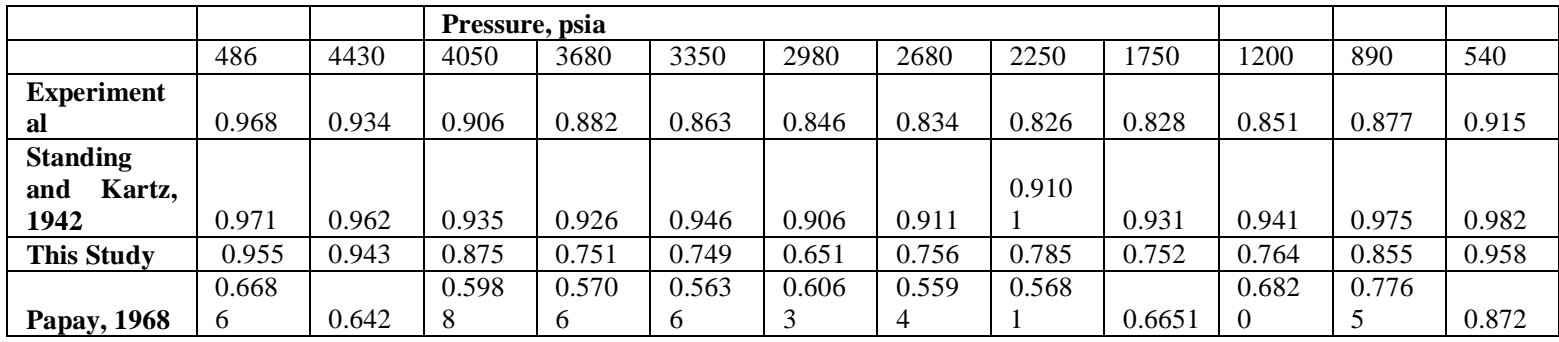

Table 5: Condensate Z-Factor Evaluation for New Correlation, Standing - Katz chart and Experiment for Gas Reservoirs

\begin{tabular}{|l|l|l|l|l|l|l|l|l|}
\hline & \multicolumn{4}{|l|}{ PRESSURE, psia } & & & \\
& & & & & & & & \\
& 5295 & 4700 & 4100 & 3500 & 2700 & 2300 & 1700 & 1100 \\
\hline Papay, 1968 & 0.88531 & 0.74298 & 0.54725 & 0.55532 & 0.53474 & 0.5588 & 0.6198 & 0.71889 \\
\hline Experimental & $\mathbf{1 . 0 0 8}$ & $\mathbf{0 . 9 3 8}$ & $\mathbf{0 . 8 9}$ & $\mathbf{0 . 8 5 5}$ & $\mathbf{0 . 8 3 3}$ & $\mathbf{0 . 8 2 9}$ & $\mathbf{0 . 8 4 8}$ & $\mathbf{0 . 8 8 3}$ \\
\hline $\begin{array}{l}\text { Standing And } \\
\text { Kartz, 1942 }\end{array}$ & $\mathbf{1 . 0 5 5}$ & $\mathbf{1 . 0 0 1}$ & $\mathbf{0 . 9 0 0 1}$ & $\mathbf{0 . 9 1 0 1}$ & $\mathbf{0 . 8 9 0 1}$ & $\mathbf{0 . 8 6 2}$ & $\mathbf{0 . 8 8 5}$ & $\mathbf{0 . 9 3 0 2}$ \\
\hline This Study & $\mathbf{1 . 0 0 0 6}$ & $\mathbf{1 . 0 0 0 5}$ & $\mathbf{0 . 9 8 9 5}$ & $\mathbf{0 . 7 8 0 5 1}$ & $\mathbf{0 . 7 3 5 1 5}$ & $\mathbf{0 . 7 8 5 4}$ & $\mathbf{0 . 8 5 2 3}$ & $\mathbf{0 . 9 0 1 5}$ \\
\hline
\end{tabular}

Table 6: Grading of Correlation Performance

\begin{tabular}{|l|l|l|l|l|l|}
\hline EOS & Dry gas & $\begin{array}{l}\text { Solution } \\
\text { Gas }\end{array}$ & $\begin{array}{l}\text { Rich } \\
\text { CO2 gas }\end{array}$ & $\begin{array}{l}\text { Condensate } \\
\text { rich gas }\end{array}$ & Average \\
\hline Yarborough \& Hall, 1973 & 7 & 9 & 9 & 9 & 8.5 \\
\hline Beggs \& Brill, 1973 & 9 & 6 & 8 & 8 & 7.75 \\
\hline Ranchuk \& Abou kassem 1975 & 5 & 2 & 6 & 4 & 4.5 \\
\hline Dranchuk, Purvis, Robison 1974 & 2 & 7 & 3 & 1 & 3.25 \\
\hline Papp, 1968 & 4 & 1 & 5 & 7 & 4.25 \\
\hline Burnett, 1979 & 8 & 5 & 7 & 2 & 5.5 \\
\hline Papay, 1968 & 3 & 3 & 2 & 5 & 3.25 \\
\hline Shell Oil Company & 6 & 8 & 4 & 3 & 5.25 \\
\hline This Study & 1 & 4 & 1 & 6 & 3.00 \\
\hline
\end{tabular}

\section{Discussion}

Several mathematical expressions fitting the SK chart have been proposed to calculate the gas compressibility factor (Papay, 1968; Yarborough and Hall, 1974; Dranchuk and Abou Kassem, ${ }^{[18]}$; Dranchk et al., 1974; Brill and Beggs, ${ }^{[20]}$, Burne 1979, Shell Oil Company. The main objectives of this study is to develop of suitable correlation(s) to estimate accurately the natural gas compressibility factor for Niger Delta gas fields, moreover, when natural gas composition is not available. Using available of natural gas database. Tables 1 through 5 show the comparison of different correlations for the four natural gas reservoirs used for this study. From the results it could be deducted that the performance of the various correlations are significant to individual reservoir due to changes in temperature and pressure.

\section{Graphical Analysis}

Figures 1 to 4 are graphical comparative results of the evaluated existing correlation, the experimental, and that of Standing and Katz chart values for the components of the four reservoirs system are shown below. This performance results shows that the proposed correlation for Niger Delta gives a brilliant result when compared with other $\mathrm{z}$-factors.

Another method we applied for selection of best correlation is called crossplots parity line. This method illustrates how most data points fall on the angle of $45^{\circ}$ parity line, and also it indicates how perfect data distribution at the centre of chart is. Figure 5 through 8 illustrate this for the new $\mathrm{z}$-factor correlation. This results show a remarkable brilliant performance for that of new correlation when compared with existing correlation used for the comparisons and can be used to predict $\mathrm{z}$-factor calculation for natural gas reservoirs in Niger Delta. 


\subsection{Grading of Correlation Performance}

Grading of correlation performance method is used to select the best correlation (s) for the natural gas compressibility factor for Niger Delta gas fields. This method also known as ranking is generally apply in natural gas industry when selecting the best predicting natural gas deviation factor. Table $\mathbf{6}$, shows the grading performance of the new z-factor and eight (8) equations of state tested with Niger Delta natural gas. The Table shows that our new developed correlation has the least average ranking of 3.00 followed by Papay and Dranchuk, Purvis and Robison with 3.25 each. While Yarborough - Hall and Beggs - Brills have the highest of 8.5 and 7.75 respectively. This therefore, means that our new developed correlation shows best correlation performance.

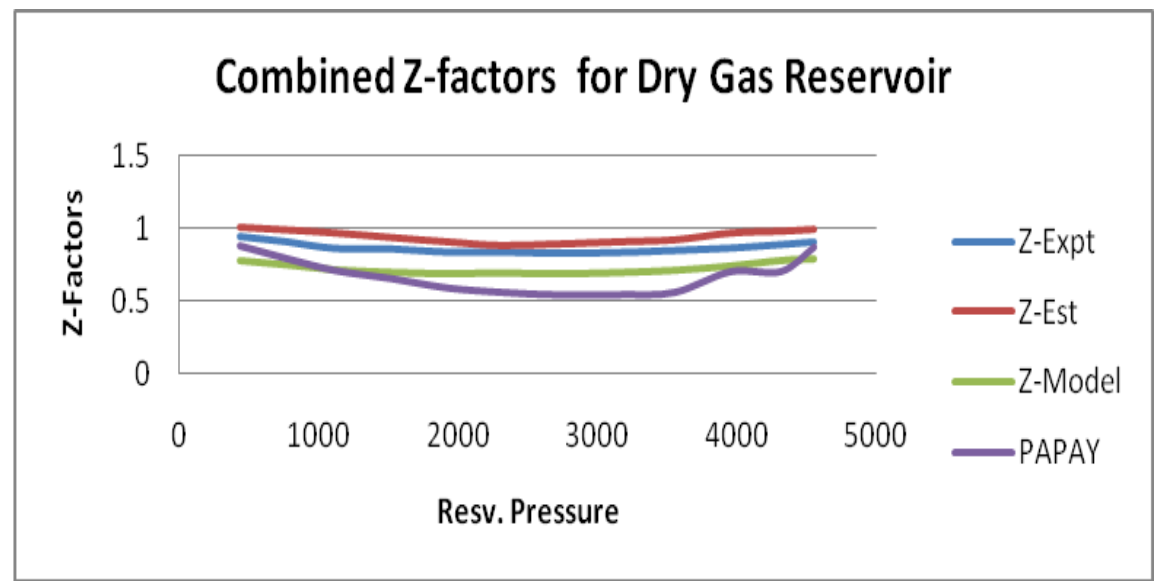

Fig.1: Plot of experiment, Papay Equation of State and Standing and Katz Chart Z-Factors for Very Dry Gas Reservoir in Niger Delta gas Fields.

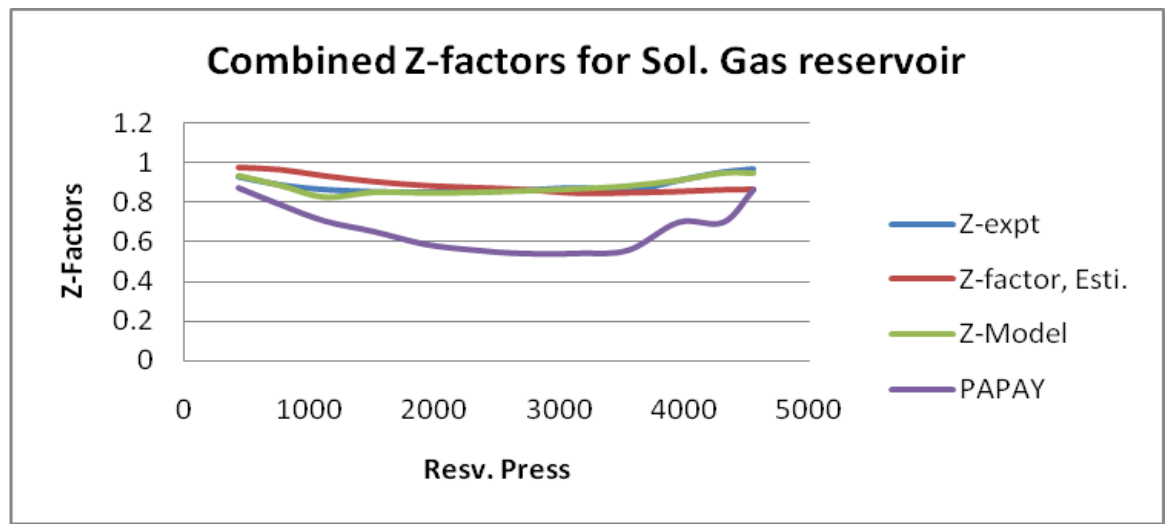

Fig. 2: Plot of experiment, Papay Equation of State and Standing and Katz Chart Z-Factors for Solution Gas Reservoir in Niger Delta gas Fields

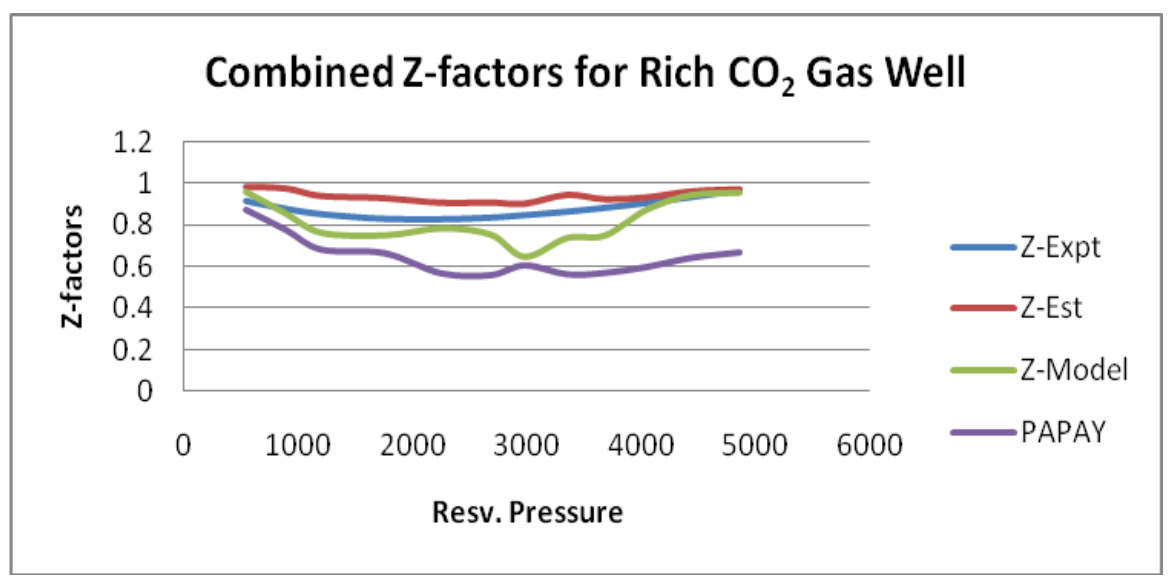

Figure. 3: Plot of experiment, Papay Equation of State and Standing and Katz Chart Z-Factors for Rich Carbon Dioxide Gas Reservoir in Niger Delta gas Fields 


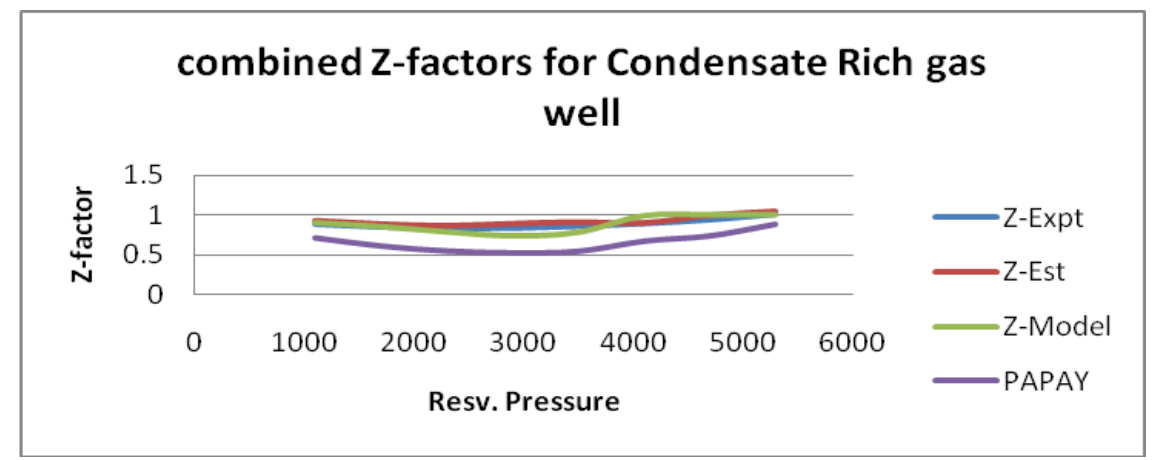

Figure. 4: Plot of experiment, Papay Equation of State and Standing and Katz Chart Z-Factors for Rich Condensate Gas Reservoir in Niger Delta gas Fields

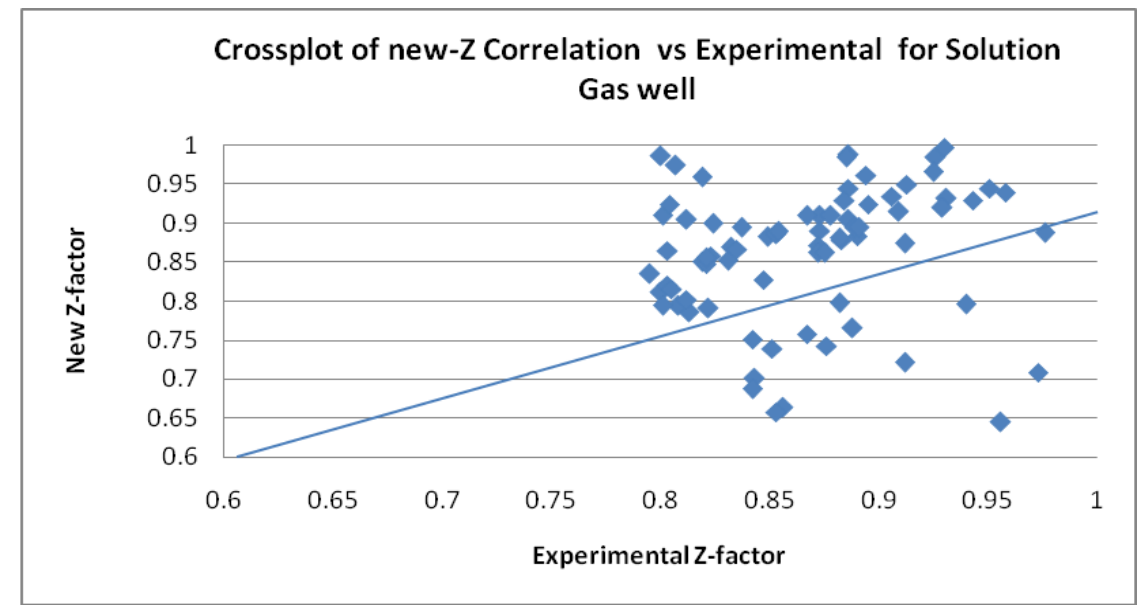

Figure. 5: Cross Plot for Z-factor Experiment vs New Z-factor Correlation for Dry Gas

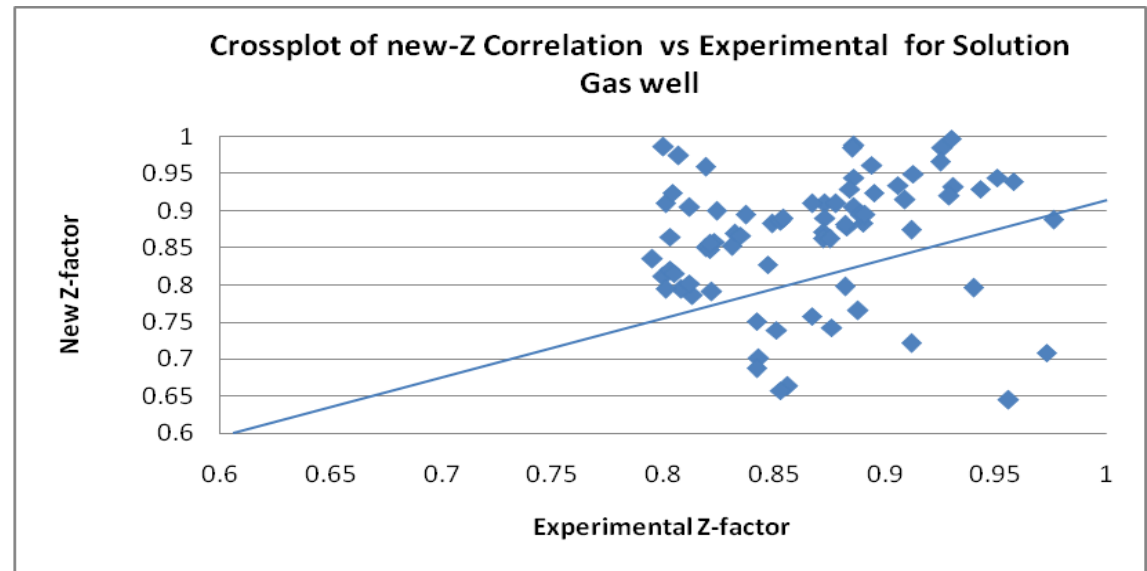

Figure. 6: Cross Plot for Z-factor Experiment vs. New Z-factor Correlation for Solution Gas Reservoir

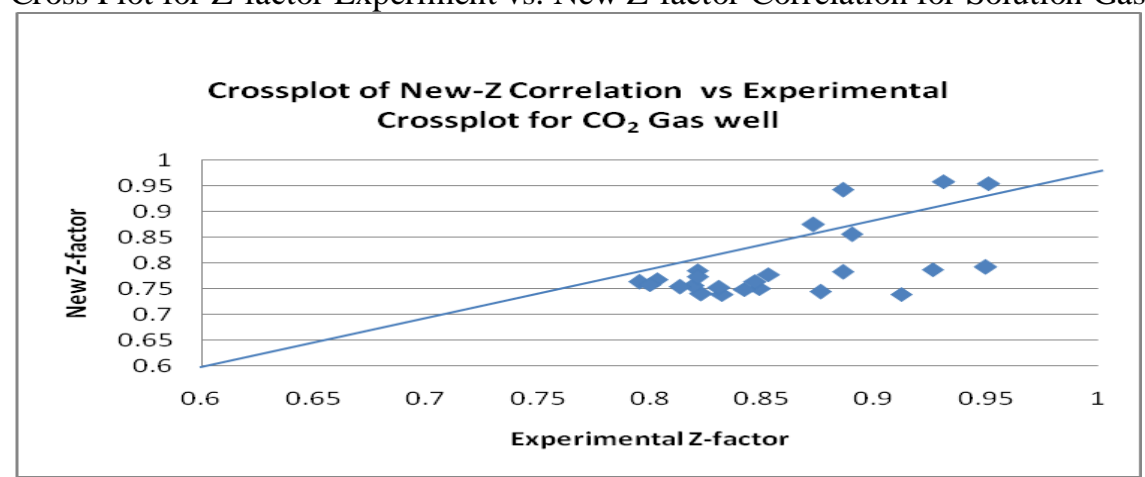

Figure. 7 : Cross Plot for Z-factor Experiment vs New Z-factor Correlation for Rich $\mathrm{CO}_{2}$ Gas Reservoir 


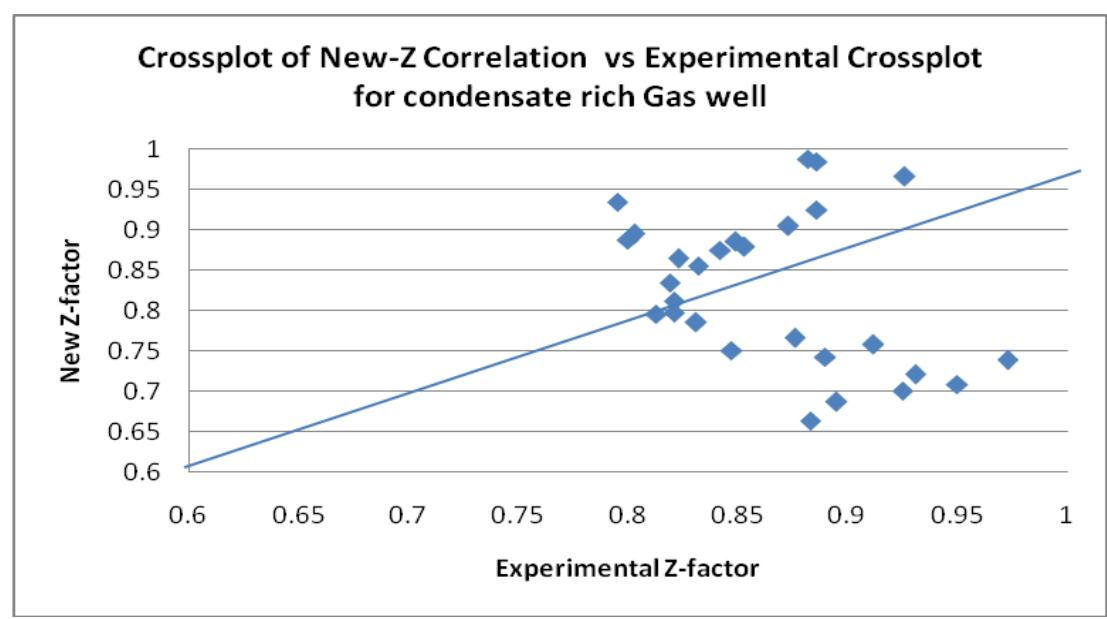

Fig. 8: Cross Plot for Z-factor Experiment vs New Z-factor Correlation for Condensate Rich Gas Reservoir

\section{Conclusions}

The objective of this work is to develop a robust z-factor correlation which can use to predict Niger

Delta natural gas easily; this was made possible with the following steps:

a. A database for Niger Delta gas field has been generated and applied to computation of z-factor. This was achieved by using PVT reports from multinational oil and gas exploration and producing companies in Niger Delta.

b. Z-factors for various equations of state and a new model equation were calculated and used for the correlations. These equations of state are routinely used in gas industries.

c. Four natural gas reservoirs system: dry gas, solution gas, rich carbon dioxide and condensate rich gas wells were separated and tested with eight equations of state and as well as the new developed compressibility factor correlation for Niger Delta gas for the finding the best correlation for Niger Delta gas fields.

d. Appropriate steps were taken for calculation of the equation z-factors; such as application of the Carr, Kohayashi-Burrows (1954) correlation to account for the natural gas impurities for accurate $\mathrm{z}$-factor values. Since Nigerian gas is sweet type, i.e. no surphur, as result the Wichert-Aziz correlation were not considered.

e. Statistical analysis of the data and graphical trends were used to be able draw the conclusions of the best correlation. And also to test performance of the new model.

f. From all the techniques applied, it was conclusively shown that the our new developed compressibility factor correlation show perfect correlation performance with the lowest standard and absolute average and best coefficient correlation (R) for the four reservoir systems tested. Best performance graphical trends when compared with the evaluated eight (EOSs). Papay Correlation was the best of the EOSs tested with least percent standard error and absolute standard error, lowest skewness and moderate kurtosis symmetry, highest correlation coefficient. Graphically, the Papay correlation shows the best trends performance in the four reservoirs system.

\section{References}

[1] MBend Statistics \& Energy Survey, Nigeria oil and gas production, 2012. Extract from Internet. 2012.

[2] World Energy, Nigeria Position in World Oil and Gas reserve as 2011.

[3] T. Ahmed, Reservoir engineering Handbook. (Butterworth -Heinemann. US. , 2001, 2nd Edition. Pp. 29-66.)

[4] O. Redlich, and J. Kwong, "On Thermodynamics of Solutions. An Equation of State. Fugacities of Gaseous Solutions." Chemical Reviews. 44, (233), 1949

[5] J. P. Brill. and H. D. Beggs, "Two-Phase flow in pipes". (Intercomp Course, The Huge, 1974)

[6] M. Benedict, G. B. Webb, and L. C. Rubin, "An Empirical Equations for Thermodynamics Properties of Light Hydrocarbons and their Mixtures: Methane, Ethane, Propane and n-Butane.” Journal of Chemistry and Physics. (8), 334, 1940.

[7] P. M. Dranchuk, and J. H Abou-Kassem, Calculation of Z Factors For Natural Gases Using Equations of State. Society of Petroleum Engineers [successor to Petroleum Society of Canada. 14(3), 1975.

[8] P. M. Dranchuk,.; R. A Purvis,.; and D. B. Robison, "Natural Gas Compressibility Factors Using the Stranding and Katz Correlations." Inst. Of petroleum Technicals Institute Series No. IP 74-008. 1974

[9] Gas Compressibility Factor With Hall-Yarborough Method. Petroleum Support. 2011.

[10] Hong Wei Xiang, The Corresponding States Principle and Its Practice: Thermodynamic, Transport and Surface Properties of Fluids. Elsevier. 2005, ISBN 0-444-52062-7.

[11] C. U. Ikoku, Natural Gas Production Engineering (Krieger Publishing Company, Malabar, Florida, 1992).

[12] J. L. Savidge Compressibility of Natural Gas. "The first requirement of gas measurement is accuracy" 2000

[13] D. L. Katz, Natural Gas Compressibility Factor in McGraw (Ed), Handbook of Natural Gas Engineering, New York 1959

[14] F. M. Kupolokun, Nigeria and the Future Global Gas Market: A Speech at the Baker Institute Energy Forum, Houston, USA, 2 May 2006. 
[15] J. Leed and R. A. Wattenbarger, Gas Reservoir Engineering. Society of Petroleum Engineers (SPE) Textbook Series, Vol. 5. USA., 1999

[16] P. Perrot, A to Z of Thermodynamics. (Oxford University Press 1998), ISBN 0-19-856552-6 1998

[17] D. Y. Peng,., and D. B. Robinson, "A New Two Constants Equation of State," Ind. Eng. Chem. Fund., 15,(59) 1976

[18] Starling, K.E., and Savidge, J. L.,(1994) Compressibility Factors of Natural Gas and Other Related Hydrocarbon Gases, American Gas Association, Transmission Measurement Committee Report 